\title{
The Application of Mental Accounts of Behavioral Finance in Internet Economy
}

\author{
Weisong Nie* \\ School of business, Macau University of Science and Technology, Macau, 999078, China \\ Corresponding Author's Email: 1325851424@qq.com
}

\begin{abstract}
With the development of e-commerce platforms, online shopping has brought many conveniences and benefits to consumers, and more and more consumers have joined the ranks of online consumption. Large-scale e-commerce and frequent merchant promotions have stimulated consumption, causing transaction records to be constantly updated. At the same time, there are many uncertainties in online shopping, leading to very subtle and complex changes in consumer psychology, making consumers aware of risks. This article studies the application of mental accounts of behavioral finance in the Internet economy, analyzes the influence of the characteristics of mental accounts on the Internet economy, and then explains the application of mental accounts of behavioral finance in the Internet economy through experiments. The experimental results show that the allocation of funds to different mental accounts is different, so Internet products can be positioned based on mental accounts.
\end{abstract}

\section{Keywords: Behavioral Finance, Mental Accounts, Internet Economy, Applied Research}

\section{INTRODUCTION}

Although more and more consumers are accepting and adopting online shopping methods, there are still many limiting factors that promote the growth of online shopping [1-2]. First of all, online products are becoming more and more abundant, resulting in oversupply in the buyer's market, making products more difficult to sell, and competing with e-commerce. Secondly, compared with traditional shopping, consumers face problems when shopping online [3-4]. For example, online shopping may not be able to promote the actual product, and it may be difficult to guarantee the quality and reliability of the product, the seller's credit is insufficient, and the consumer's confidence is insufficient. For online payment, consumers worry about credit card leakage and privacy issues [5-6]. In the process of retrieving product information, it is difficult to determine the reliability of data information, so that consumers stay away from distrust and ultimately rely on offline shopping. Compared with traditional offline shopping, consumers' online shopping is considered to be more psychological and the purchase process is also more complicated. From a business perspective, online research on consumer psychological behavior is very important [7-8].

Regarding the research on mental accounts of behavioral finance, some researchers studied the property distribution of the best investment portfolio from the perspective of mental accounts, for the first time, it is proposed to parameterize the implicit risk of the total investment portfolio to achieve an allocation balance, then the allocation of assets and the composition of the optimal investment portfolio of the account depends on these parameters. Finally, changing any mental account objectives will affect the composition of the optimal investment portfolio [9]. Some researchers also pointed out that personal cognition and mental behavior always have an impact on some daily decision-making behaviors, and the financial aspect is no exception. Therefore, the impact of mental accounts on family financial expenditures is explored, and the stratification potential is first used. The variable model determines the mental account, then uses the questionnaire method to collect 425 structured questionnaires, and expands consumers' awareness of behavioral finance through the analysis of the results [10]. Some researchers have proposed that the optimal decision-making plan is an important content of enterprise project management. Therefore, the introduction of behavioral finance into the project decision-making process is mainly to combine mental accounts with Markowitz's investment portfolio ideas to establish combine the best selection model, and finally, experiments prove that the combined method is better than the traditional model [11]. Some researchers also 
pointed out that the mental account (HAMA) is of great significance for determining the risk appetite of investors, so it was verified through experiments. The experimental results found that the risk aversion and the ratio of bonds to stocks increase with the investment period of the mental account. And fell investors who give high value to the upside potential tend to choose a portfolio with more important asymmetric distribution and fine peak distribution [12]. In summary, there are still many research results on mental accounts, but there are relatively few researches on the application of mental accounts in behavioral finance to the Internet economy.

This article studies the application of financial behavior mental accounts in the Internet economy, provides a rough theoretical introduction to mental accounts based on relevant data, and analyzes the impact of financial behavior mental accounts on the Internet economy, and then validates them through experiments and draws conclusions.

\section{RESEARCH ON MENTAL ACCOUNTS OF BEHAVIORAL FINANCE}

\subsection{Characteristics of Mental Accounts}

\section{(1) Irreplaceable}

The principle of non-substitution runs counter to traditional economic principles. Traditional economics believes that currencies can replace each other. But in reality, money is often divided into different accounts, and money in different accounts cannot be exchanged for each other. For example, hard-earned money is seldom used for luxury enjoyment and investment, and seldom used for daily necessities and savings. But for the wealth we acquire randomly, we tend to enjoy luxury goods and investments.

\section{(2) Hedonism}

People who make decisions in dangerous situations have three characteristics. First, the decision depends on the report (report dependency). In other words, it sets the benchmark in advance when making a decision, and sets the relative position of the result at the reference point (gain or loss) according to the absolute level of the result. If the result is higher than the reference point, people will think it is profitable, if the result is lower than the reference point, people will think it is a loss. Second, the sensitivity of the result decreases as the distance from the reference point increases. In other words, people are more likely to perceive changes in profit and loss around the reference point. Third, people's perception of loss is much greater than perception of profit. For example, the happiness of a 200 yuan bonus is far less than the pain of losing 200 yuan.

\subsection{The Impact of Mental Accounts of Behavioral Finance on the Internet Economy}

Consumers tend to separate different accounts by default due to their own psychological consumption, but in fact they are all the same account, but this is the consumer's psychological account. Mental account problems usually lead to some unusual consumer behavior, which is a phenomenon that cannot be explained by traditional economic theory. The same is true for online finance. From the perspective of consumer mental accounts, Internet finance is your account. Among the current major users of Internet lending, the $90 \mathrm{~s}$ accounted for the majority. This is because since the 90s, most people can only engage in simple jobs and have limited personal wealth. Funds can only be kept in the short-term, not long-term. In addition, for current commercial banks, the short-term investment savings rate is far lower than the ratio of traditional online loan investment savings rate. Consumers choose to invest through online loans to seek higher returns with the help of the Internet. Therefore, it is constantly growing. However, bank loan savings are generally risk-free savings. Our country's current regulation and supervision measures for network security are not sound enough, and the risks are relatively high. In the context of network lending, there are not many credit cards and psychological accounts.

\subsection{Data Analysis}

In this article, we refer to the research results of consumer market incentive theory and price sensitivity theory analysis, and use the price utility equation of consumers who purchase goods online as the product of commodity prices and consumer price sensitivity. Assuming that $\mathrm{P}$ is the price of goods purchased by consumers, and $\mathrm{S}$ is a parameter indicating the sensitivity to consumer prices, the utility price equation can be expressed as follows:

$$
\mathrm{U}_{p}=P_{i} * P S_{i}
$$

Among them, the PS value sensitivity is an exponential function, which can be expressed as the difference between the actual price $\mathrm{P}$ of the commodity and the price expected by consumers' psychology as follows:

$$
P S_{i}=-\lambda^{P_{i}-P_{t}}+V
$$

Here, the parameter $\lambda>1, \mathrm{~V}$ is a constant and depends on the financial income of the main consumers. When the actual price of the product $\mathrm{P}$ is higher than the consumer's expected price, the lower the purchase motivation, the higher the price sensitivity, so there is a negative sign in front of $\lambda$. 


\section{EXPERIMENTAL VERIFICATION OF THE INFLUENCE OF MENTAL ACCOUNTS OF BEHAVIORAL FINANCE ON THE INTERNET ECONOMY}

\subsection{Experimental Analysis}

Since the main purpose of this article is to study the application of behavioral mindfulness accounts in the Internet economy, we will study irrational consumer decision-making behaviors from the perspective of behavioral mental accounts. Therefore, the results should be determined in advance before the experiment. (1) When future consumption remains unchanged: the current income is sufficient, and the willingness to purchase with current income is stronger than the willingness to consume with demand deposits. In the current situation of insufficient income, the willingness to buy is weaker than the willingness to consume. (2) When future consumption is uncertain, the tendency to buy with current income is stronger than the willingness to buy with current deposits.

\subsection{Experimental Data}

In this article, 120 working urban residents were randomly selected to participate in this 5-minute experiment. All subjects work in a local company and live in this city. Among them, 7 people are under 20 years old, $5 \%, 76$ people are $20-30$ years old, $58 \%, 10$ people are $30-40$ years old, and 10 people are $40-50$ years old. It can be seen that the age of individuals is concentrated in the 20-50 years old age group, and most of them are young (20-30 years old). Among them, 65 men account for $50 \%$, and 65 women account for $50 \%$. The ratio of men to women is the same.

\subsection{Experimental Design}

In the experiment, the experimenter received a mental account and confirmed the assignment of the mental account. At that time, an unstructured investigation will be conducted. The biggest feature of the questionnaire method is that it is very standardized and can receive a large amount of data in a short time. The questionnaire survey method is a questionnaire survey that strictly follows a statistical design and a stable structure, collect a lot of sub-account data for mental accounts. In previous surveys, questionnaire-style unstructured questionnaires can be answered freely according to the actual situation, which helps to discover more mental accounts.

\subsection{Data Processing}

(1) Basic data integration: A basic data is stored in multiple database systems. You need to design your own collection logic, summarize the data in various locations as needed, fill in the missing data, unify the caliber, and clean up the dirty data.

(2) Selection of information and data: pick out the information closely related to its needs from a large amount of information. Various types of data are selected according to the specific objectives to be selected, including as much as possible to limit the conversion, integration and analysis of various types of data within the scope of mining, and to improve the quality of mining.

(3) Data source preprocessing: The traditional data source preprocessing method is to extract and analyze a large amount of data information in order to obtain various data used in the entire data development process closely related format, noise.

\section{ANALYSIS OF EXPERIMENTAL RESULTS}

\subsection{Decisions on Different Incomes}

This paper studies the influence of mental accounts of behavioral finance on the Internet economy, and collects the distribution of different incomes to funds through questionnaire surveys. The relevant data results are shown in Table 1:

Table 1. Decision results for different incomes

\begin{tabular}{|c|c|c|c|}
\hline & 5000 & 10000 & 15000 \\
\hline Consumption & $60 \%$ & $43 \%$ & $35 \%$ \\
\hline Savings & $30 \%$ & $35 \%$ & $32 \%$ \\
\hline Invest & $10 \%$ & $32 \%$ & $43 \%$ \\
\hline
\end{tabular}




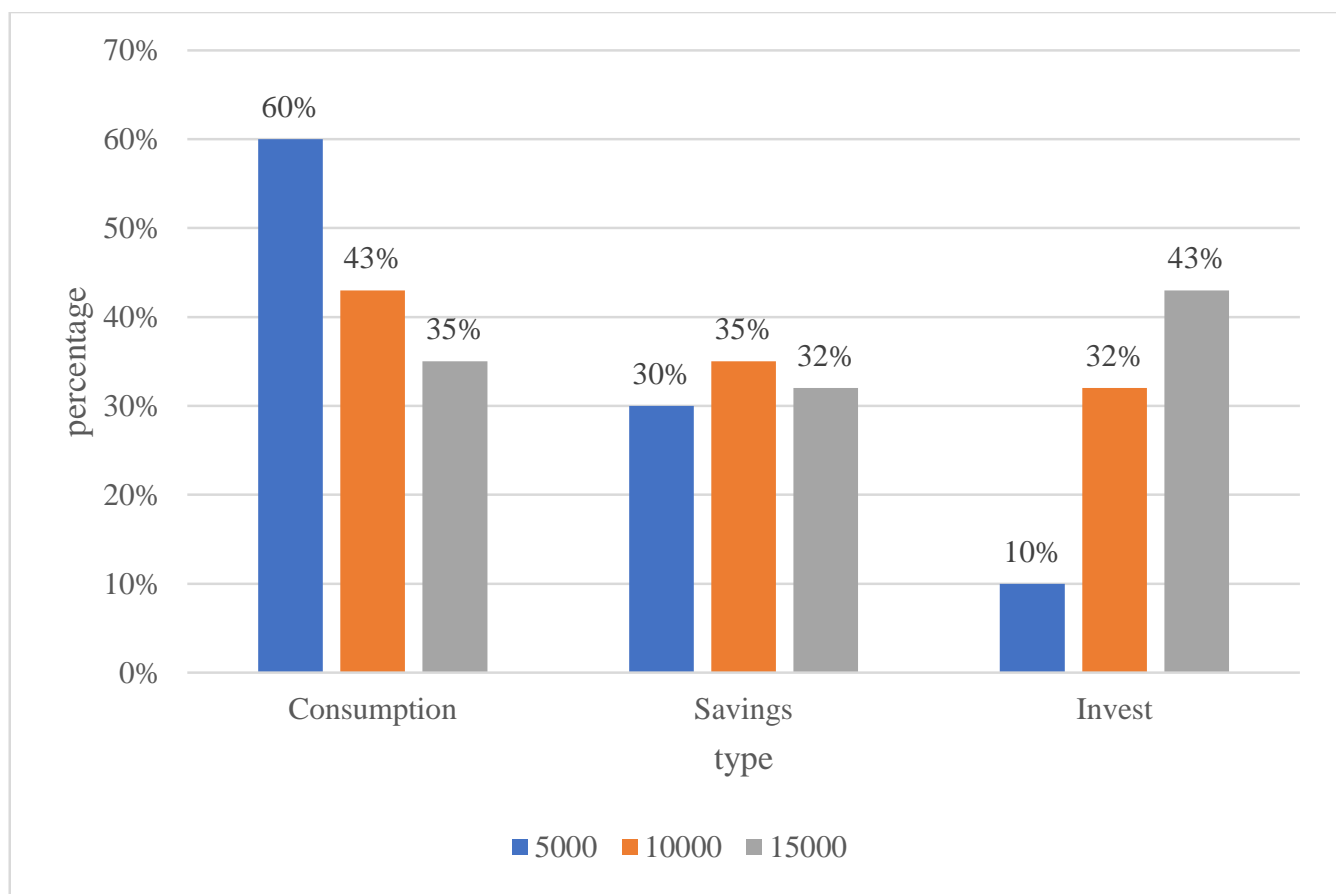

Figure 1. Decision results for different incomes

It can be seen from Figure 1 that under different income situations, the distribution of funds is different. In consumption, as the income of wages is higher, the proportion of consumption is lower, and then there is no significant difference in savings. The difference is that the higher the investment income, the higher the investment amount.

\subsection{Consumption of Product Prices by Different Incomes}

This paper studies the influence of mental accounts of behavioral finance on the Internet economy, and collects the consumption of different incomes on product prices through questionnaire surveys. The relevant data results are shown in Table 2:

Table 2. Consumption of different incomes on product prices

\begin{tabular}{|c|c|c|c|}
\hline & 5000 & 10000 & 15000 \\
\hline 100 & $67 \%$ & $78 \%$ & $89 \%$ \\
\hline 500 & $34 \%$ & $56 \%$ & $67 \%$ \\
\hline 1000 & $21 \%$ & $34 \%$ & $45 \%$ \\
\hline 1500 & $2 \%$ & $32 \%$ & $43 \%$ \\
\hline
\end{tabular}

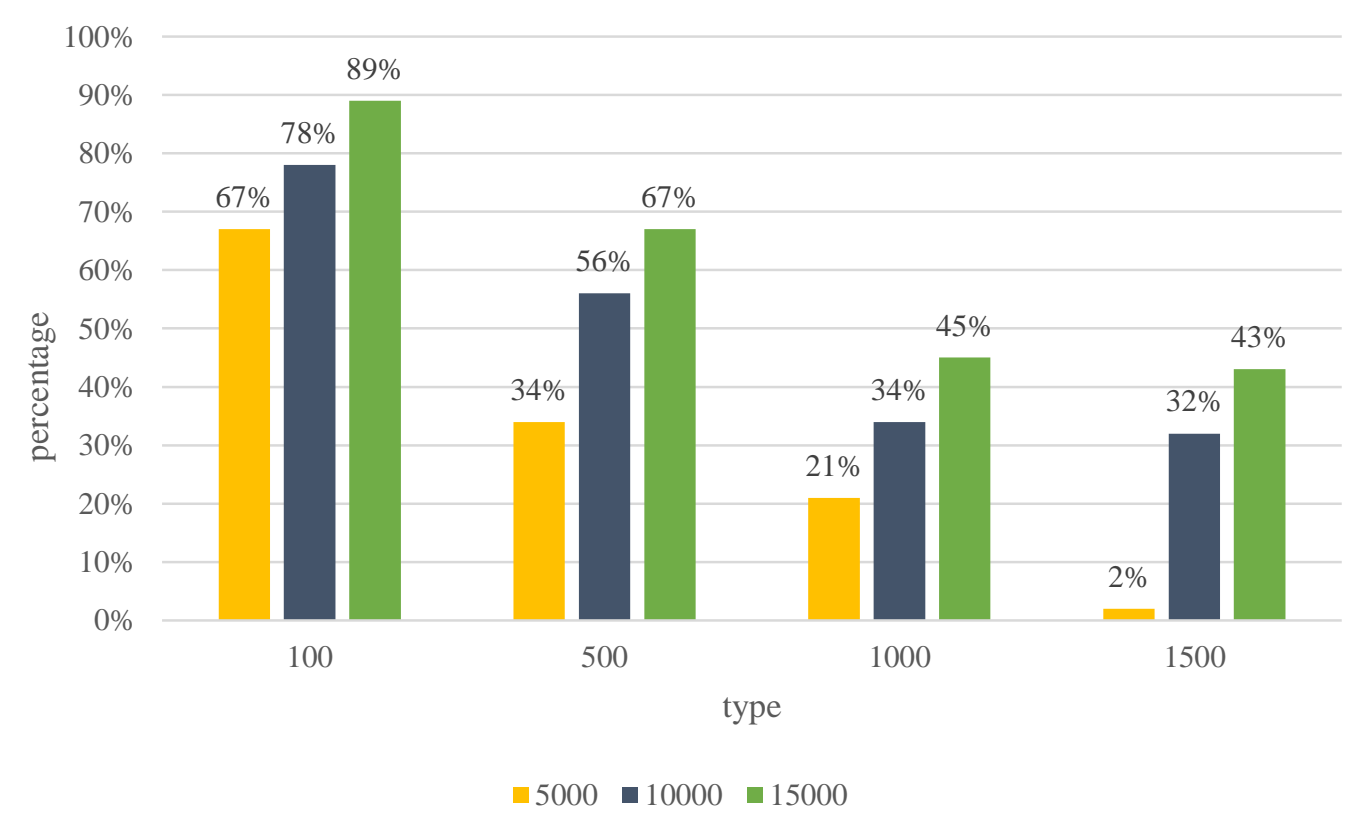

Figure 2. Consumption of different incomes on product prices 
It can be seen from Figure 2 that due to differences in income, the prices of products consumed are also different. Consumers compare the expected price of the product with the actual price of the product. If the actual price is equal to the expected price, the consumer decides to buy. As a product begins to decline slowly at a constant rate over time, the actual price of the product is getting closer and closer to the psychological expectations of consumers, who will become sensitive to these prices that have not yet purchased the product, and follow that over time over time, some online consumer behaviors will develop, and the number of consumer purchases will begin to increase.

\section{CONCLUSION}

In this article, I have studied the application of behavioral financial mental accounts in the Internet economy, and have a general understanding of mental accounts, and then verify the application of mental accounts in the Internet economy through experiments. The experimental results show that different mental accounts have different price acceptance status of the product, and the consumption status of the product is also different. If the expected price of the product is different from the actual price of the product, consumers will make different purchasing decisions, which can be used as a basis to purchase Internet products for positioning.

\section{REFERENCES}

[1] Salmon D, Salmon D. An impact evaluation of an education \& support programme to promote routine antenatal enquiry for domestic violence[J]. Revista De Psiquiatría Y Salud Mental, 2017, 2(2):66-71.

[2] Ruhli E, Sachs S, Schmitt R, et al. Innovation in Multistakeholder Settings: The Case of a Wicked Issue in Health Care[J]. Journal of Business Ethics, 2017, 143(2):289-305.

[3] Baker H K, Kumar S, Goyal N, et al. How financial literacy and demographic variables relate to behavioral biases[J]. Managerial Finance, 2019, 45(1):124-146.

[4] Bakker H, Veldhoven M V, Gaillard T, et al. The functioning of rescue workers in life tasks: development of a test[J]. International Journal of Emergency Services, 2019, 9(1):34-46.

[5] Fossa P, Gonzalez N, Montezemolo F. From Inner Speech to Mind-Wandering: Developing a Comprehensive Model of Inner Mental Activity Trajectories[J]. Integrative Psychological and Behavioral Science, 2018, 53(2):298-322.

[6] Merkle C, J Müller-Dethard, Weber M. Closing a mental account: the realization effect for gains and losses[J]. Experimental Economics, 2020(4):1-27.
[7] Varin M, Baker M, Palladino E, et al. At-a-glance Canadian Chronic Disease Indicators, 2019 Updating the data and taking into account mental health $[\mathrm{J}]$. Health Promotion and Chronic Disease Prevention in Canada, 2019, 39(10):281-288.

[8] Alexander, K, Koch, et al. Goals and bracketing under mental accounting[J]. Journal of Economic Theory, 2016, 162(Mar.):305-351.

[9] Schwartz D R, Stratton N, Hart T A. Minority Stress and Mental and Sexual Health: Examining the Psychological Mediation Framework Among Gay and Bisexual Men[J]. Psychology of Sexual Orientation and Gender Diversity, 2016, 3(3):313324.

[10] Nagel, Jennifer. Factive and nonfactive mental state attribution[J]. Mind \& Language, 2017, 32(5):525544.

[11] Sungyong, Chun, Eunseong, et al. The Influence of Mental Accounting Period, Risk Aversion, and Pain of Paying on the Purchase Intention for Insurance Products[J]. Financial Planning Review, 2017, 10(3):87-106.

[12] Huang J Q, Antonides G, Christian H K, et al. Mental accounting and consumption of self-produced food[J]. Journal of Integrative Agriculture, 2021, 20(9):2569-2580. 